\section{Revista Signos}

2010 / 43

Número Especial

Monográfico $\mathrm{N}^{\circ} 1$

205-225

\title{
Teoria da relevância e análise sócio-retórica de gêneros textuais: Análise de respostas em cartas- consulta diretas e indiretas
}

\author{
Fábio Rauen \\ Universidade UNISUL \\ Brasil
}

\begin{abstract}
Resumo: Segundo Simoni (2004), há dois padrões para o gênero carta-consulta nos Jornais Folha de S. Paulo e $\mathrm{O}$ Globo, cartas-consulta diretas e indiretas, conforme as respostas sejam citadas ou reportadas no terceiro movimento, o de 'fornecer uma resposta'. Com base na teoria da relevância e analisando novamente os 68 exemplares de carta-consulta coletados pela autora, argumenta-se neste artigo que relações de relevância permitem refinar essa tipologia e o próprio conceito desse gênero. Assim, por cartas-consulta definem-se cartas do leitor, publicadas em seções específicas de um jornal, contendo uma consulta ou demanda, para a qual se transcrevem ou relatam respostas ou réplicas da redação desse jornal, de colaboradores especialistas ou de entidades envolvidas na demanda. Cartas-consulta com respostas diretas são cartas dos leitores contendo consultas, para as quais se transcrevem respostas da redação ou de colaboradores especialistas. Cartas-consulta com respostas indiretas são cartas dos leitores contendo demandas ou consultas, para as quais se relatam satisfações ou respostas das entidades envolvidas na demandas ou consultas.
\end{abstract}

Palavras-Chave: Pragmática cognitiva, teoria da relevância, teoria sócio-retórica, gêneros textuais, carta-consulta.

Recibido: 20-XI-2009

Aceptado: 24-V-2010

Correspondencia: Fábio Rauen (fabio.rauen@unisul.br). Universidade do Sul de Santa Catarina. Avenida José Acácio Moreira 787, Dehon Turbão. CEP 88.704-900. Santa Catarina, Brasil. 


\section{Teoría de la relevancia y análisis socio-retórico de géneros textuales Análisis de respuestas en cartas de consulta directas e indirectas}

Resumen: De acuerdo con Simoni (2004), existen dos normas para el género carta de consulta en los periódicos Folha de S. Paulo y $\mathrm{O}$ Globo, las cartas de consulta directas y indirectas, conforme las respuestas son citadas o referidas en el tercer movimiento: 'dar una respuesta'. Con base en la teoría de la relevancia y en la reanálisis de 68 ejemplares de carta de consulta recogidos por la autora, se argumenta en este artículo que relaciones de relevancia permiten perfeccionar esta tipología y el propio concepto de género. Así, por cartas de consulta se definen cartas de lectores publicadas en secciones específicas de un periódico que contienen una consulta o demanda, para las cuales se transcriben respuestas o réplicas de la redacción de este periódico, de colaboradores expertos o de entidades que participan en la demanda. Cartas de consulta con respuestas directas son las cartas de los lectores con preguntas, cuyas respuestas se transcriben a partir de la redacción o de colaboradores expertos. Cartas de consulta con respuestas indirectas son las cartas de los lectores que contienen demandas o consultas para las cuales se declararon satisfacciones o respuestas de las entidades que participan en las demandas o consultas.

Palabras Clave: Pragmática cognitiva, teoría de la relevancia, teoría socio-retórica, género, carta de consulta.

\section{Relevance Theory and socio-rhetorical analysis of text genres: Analysis of answers in direct and indirect query-letters}

Abstract: According to Simoni (2004), there are two standards for the query-letter genre in Folha de S. Paulo and $O$ Globo Brazilian Journals, direct and indirect, as the answers are quoted or reported in the third movement: 'provide an answer.' Based on relevance theory, the 68 query-letters collected in Simoni's work were reanalyzed in this study, indicating that relevance relations allow us to refine this distinction and the definition of the genre itself. Therefore, query-letters are reader's letters, published in specific sections of a newspaper, containing a query or demand, whose answers or replicas of editorial staffs, specialists or involved entities are quoted or reported. Query-letters with direct answers are reader's letters, containing queries, whose answers of editorial staff or specialists are quoted; and query-letters with indirect answers are reader's letters, containing demands or consultations, whose satisfaction or responses of the involved entities are reported.

Key Words: Cognitive pragmatics, relevance theory, socio-rhetorical theory, genre, query-letter. 


\section{INTRODUÇÃO}

Em 'Relevance and genre: Theoretical and conceptual interfaces' (Bazerman, Bonini \& Figueiredo, 2009), investiguei possíveis conexões da teoria da relevância (Sperber \& Wilson, 1995) com as análises sócio-retóricas de gêneros textuais identificadas com os estudos de Swales (1990, 1992, 1998). Analisando uma carta-consulta direta do corpus de Simoni (2004), observei que movimentos e passos retóricos daquele texto gravitaram em torno da complementação de um dos constituintes lógicos da questão do consulente, sugerindo que estruturas genéricas derivam de algo mais essencial: relações de relevância.

Para Simoni (2004: 69), uma carta-consulta é "um texto que circula em seções fixas do jornal reservadas à correspondência dos leitores" com dois momentos característicos: o questionamento do leitor e o texto-resposta "destinado a auxiliar o leitor/escritor no que diz respeito à questão formulada por ele”. Para ela, as cartas-consulta apresentam três movimentos retóricos, cada qual com um enunciador específico: o jornalista E1 identifica o texto, além de formatá-lo integralmente; o consulente E2 formula uma questão; e o respondente E3 fornece uma resposta. Mais ainda, conforme as respostas sejam citadas ou reportadas, as cartas-consulta podem classificadas como diretas ou indiretas.

Neste artigo, analiso esses dois tipos de respostas, argumentado que a aplicação dos conceitos de forma lógica, explicatura e implicatura (Sperber \& Wilson, 1995; Carston, 1988) permite descrever e explicar adequadamente os processos ostensivo-inferenciais envolvidos nas interações viabilizadas por esse gênero. Assim, depois de breve revisão da teoria na primeira seção, analiso as respostas das cartas-consulta indiretas e diretas selecionadas por Simoni (2004) nas três seções seguintes, verificando se as diferenças encontradas são opcionais ou constrangidas, para então rever o próprio conceito de carta-consulta e de seus subtipos nas conclusões.

\section{Teoria da relevância e gênero}

Em teoria da relevância, pressupõe-se que a cognição humana se orienta para a relevância. Argumenta-se que uma informação nova (ou novamente apresentada) é relevante num contexto cognitivo, quando ela interage com esse contexto para gerar efeitos cognitivos de três espécies: o de fortalecimento de uma suposição contextual; o de contradição e eliminação de uma suposição contextual; e o de combinação dessa informação com uma suposição contextual para gerar implicações contextuais: conclusões que se deduzem da integração da informação, mas que nunca se deduzem da informação nova ou do contexto isoladamente.

Tomem-se o título e o primeiro enunciado da carta-consulta analisada em Rauen (2009): 
(1) Gaveta.

(2) Tenho um contrato de gaveta registrado em cartório em $1985^{1}$.

Se um leitor supuser em (1) que o texto trata de uma consulta sobre defeitos de algum móvel, essa primeira suposição é contradita e eliminada em (2), pois a carta se refere a um 'contrato de gaveta'. Se um leitor supuser de imediato que o texto se trata de uma consulta sobre 'contratos de gaveta', essa suposição é fortalecida pelo enunciado (2). Ainda, se o leitor conhecer o sistema brasileiro de financiamento da habitação, o enunciado (2) pode combinar-se com suposições memorizadas, gerando a conclusão implicada (implicação contextual) de que, por exemplo, o imóvel é financiado².

Veja-se uma possível cadeia de suposições ' $S$ ' para essa inferência:

$\mathrm{S}_{1}$ - 'Contratos de gaveta' referem-se a imóveis financiados;

$S_{2}$ - Uma pessoa tem um 'contrato de gaveta' registrado em cartório em 1985;

$\mathrm{S}_{3}-\mathrm{Se} \mathrm{S}_{1}$ e $\mathrm{S}_{2}$, então $\mathrm{S}_{5}$ (por modus ponens conjuntivo);

$\mathrm{S}_{4}-\mathrm{Se} \mathrm{S}_{1}$, então $\mathrm{S}_{5}$ (por eliminação-e);

$\mathrm{S}_{5}$ - $\mathrm{O}$ imóvel da pessoa foi financiado (por afirmação do antecedente).

Informações são relevantes quando geram efeitos cognitivos. Quanto maiores os efeitos, maior é a relevância. Contudo, além dos efeitos, consideram-se os gastos para obtê-los. Informações são mais relevantes quanto menores forem os esforços cognitivos para depreendê-las. Comparem-se duas versões para o enunciado (2):

(2a) Tenho um contrato de gaveta registrado em cartório em 1985.

(2b) Não é verdade que não tenho um contrato de gaveta registrado em cartório em 1985.

Supostamente, o enunciado (2a) é mais fácil de processar e, por hipótese, sendo iguais as condições, ele é mais relevante do que o enunciado $(2 \mathrm{~b})$, visto que $(2 \mathrm{~b})$ inclui a forma lógica do enunciado (2a) como parte de sua forma lógica.

Se a cognição se orienta para a relevância, então recursos cognitivos são alocados aos inputs mais relevantes para maximizá-la. Trata-se do 'princípio cognitivo de relevância', que prediz que 'a cognição humana tende a ser dirigida para a maximização da relevância' (Sperber \& Wilson, 1995). Mas como os seres humanos escolhem conscientemente ou automaticamente a quais inputs prestar atenção, em que contexto processá-los e quando parar? 
Numa comunicação intencional aberta, escritores produzem estímulos ostensivos que fornecem evidência para os leitores inferirem certa conclusão. Comunicar é oferecer informação, e essa oferta autoriza que a informação seja esperada como relevante o suficiente para merecer processamento. Como há várias interpretações linguisticamente possíveis e potencialmente relevantes para os enunciados, a interpretação escolhida será a que melhor satisfizer essa presunção ou expectativa de relevância.

Um enunciado é relevante quando contém ao menos efeitos cognitivos suficientes com um custo de processamento suficientemente baixo para merecer atenção. Isso constitui a noção de 'relevância ótima', que envolve duas cláusulas: a) a de que o enunciado deve ser ao menos relevante o suficiente para merecer processamento; e, b) a de que o enunciado deve ser o mais relevante compatível com as habilidades e as preferências do escritor.

A cláusula (a) varia individualmente e circunstancialmente. Para ser relevante o suficiente, o enunciado deve ser mais relevante do que qualquer coisa que o leitor poderia ter prestado atenção, se ele não houvesse sido produzido. De acordo com essa cláusula, o leitor deve tomar o significado codificado linguisticamente e levá-lo a um ponto onde ele é ao menos relevante o suficiente para merecer ser processado. Isso ocorre quando se obtém ao menos efeitos cognitivos suficientes para um esforço de processamento suficientemente pequeno.

De acordo com a cláusula (b), espera-se que os escritores produzam o enunciado mais relevante possível, conforme suas habilidades ou preferências. Isso libera o leitor de considerar outras interpretações menos acessíveis depois de achar uma interpretação aceitável, permitindo predizer um procedimento de compreensão concreto para descobrir a melhor hipótese sobre o significado do escritor: o leitor deve seguir um caminho de menor esforço ao computar efeitos cognitivos: a) considerando interpretações (atribuições de referência, contextos, etc.) em ordem de acessibilidade; e, b) parando quando sua expectativa de relevância é satisfeita (ou abandonada) (Wilson, 2004).

Posto isso, pode-se definir um 'princípio comunicativo de relevância': cada enunciado (ou outro estímulo ostensivo) cria uma presunção de sua própria relevância ótima (Sperber \& Wilson, 1995)³.

Em teoria da relevância, um enunciado consiste num conjunto estruturado de conceitos (rótulos ou endereços com entradas lógicas, linguísticas e enciclopédicas) na forma de uma proposição ou forma lógica. Em geral, as sentenças que veiculam os enunciados apresentam-se semanticamente incompletas. Assim, com base na codificação linguística e seguindo uma rota de esforço mínimo, o leitor enriquece os inputs da forma lógica para obter o significado explícito (explicaturas) e completá-lo em nível implícito (implicaturas), até que a interpretação se conforme com sua expectativa de relevância ${ }^{4}$. 
Os níveis representacionais podem ser vistos no excerto a seguir, que compõe as ações retóricas de 'identificar o texto' e 'formular uma questão' da carta-consulta:

(1) Gaveta

(2) Tenho um contrato de gaveta registrado em cartório em 1985.

(3) Em meio de 1996, quitei o imóvel com o FGTS5.

(4) A Caixa me informou agora que a proprietária do imóvel tem que assinar o contrato de quitação.

(5) Mas há anos não tenho mais contato com ela.

(6) 0 que devo fazer?

(7) Luiz Silva

(8) Rio de Janeiro

Nesse excerto, o enunciado (6), agora (6a), contém, por hipótese, a forma lógica (6b):

(6a) 0 que devo fazer?

(6b) dever fazer, alguém, algo.

A forma lógica (6b) é semanticamente incompleta, porque dois constituintes lógicos estão em aberto: os sintagmas nominais sujeito e objeto de 'dever fazer'. Essa forma lógica deve ser desenvolvida para constituir-se numa proposição completa passível de ser verdadeira ou falsa.

No enunciado (6a), uma pergunta, a forma proposicional corresponde a uma interpretação de um pensamento do escritor que pode ser uma interpretação de um pensamento desejável ${ }^{6}$. Por hipótese, o leitor recupera sua forma lógica e a integra numa descrição com a forma ' $O$ escritor está perguntando Qu-P', onde 'Qu-P’ é uma pergunta indireta'.

A explicatura de (6) pode ser desenvolvida como se segue:

(6b) dever fazer, alguém, algo.

(6c) dever fazer, Luiz Silva, QU.

Além disso, pode-se encaixar essa forma lógica numa descrição de nível mais alto, como em (6d-e), considerando o ato de fala em jogo:

(6d) 0 enunciador 2 pergunta algo (dever fazer, alguém, algo).

(6e) Luiz Silva pergunta (dever fazer, Luiz Silva, QU). 
A formulação (6e), embora próxima do passo retórico de 'solicitar uma resposta', ainda não capta a dúvida de Luiz Silva. Isso só é possível com um contexto suficientemente rico de suposições. Para enriquecer esse contexto, o jornalista ‘intitula a carta', 'delineia o cenário' e 'apresenta o problema'. A leitura desses enunciados aciona um conjunto de suposições memorizadas para explicitar o constituinte lógico relevante da questão. Veja-se:

$\mathrm{S}_{1}$ - $O$ texto é uma consulta;

$\mathrm{S}_{2}$ - A consulta é sobre um 'contrato de gaveta';

$\mathrm{S}_{3}$ - Luiz Silva tem um 'contrato de gaveta' registrado em cartório em 1985;

$\mathrm{S}_{4}$ - $\mathrm{O}$ 'contrato de gaveta' de Luiz Silva refere-se a um imóvel;

$\mathrm{S}_{5}$ - Luiz Silva quitou o imóvel com recursos do FGTS em 1996;

$\mathrm{S}_{6}$ - O FGTS pode ser usado para quitar imóveis;

$\mathrm{S}_{7}$ - A Caixa Econômica Federal informou a Luiz Silva que a proprietária do imóvel tem que assinar o contrato de quitação em 1996;

$\mathrm{S}_{8}$ - $O$ financiamento do imóvel era da Caixa Econômica Federal;

$\mathrm{S}_{9}$ - 0 proprietário do imóvel não é o titular do 'contrato de gaveta' para a Caixa Econômica Federal.

Segue-se o enunciado (5), que explicita o problema de Luiz Silva e pode ser uma pista para inferir o motivo da consulta.

$\mathrm{S}_{10}$ - Luiz Silva não tem mais contato com a proprietária do imóvel há anos;

$\mathrm{S}_{11}$ - Contratos de gaveta devem ser formalizados;

$\mathrm{S}_{12}-\mathrm{Se}_{10}$ e $\mathrm{S}_{11}$, então $\mathrm{S}_{14}$ (por modus ponens conjuntivo);

$\mathrm{S}_{13}-\mathrm{Se} \mathrm{S}_{11}$, então $\mathrm{S}_{14}$ (por eliminação-e);

$\mathrm{S}_{14}$ - Luiz Silva possivelmente não sabe como formalizar o contrato de gaveta de Luiz Silva com a proprietária do imóvel (por afirmação do antecedente).

Com esse conjunto de suposições e inferências, é possível estabelecer por hipótese uma proposição completa para o enunciado (6) em (6i), que inclui o ato de fala do jornalista E1 (mediador da interação) e, provavelmente, é suficientemente relevante.

(6f) 0 enunciador 2 pergunta algo (dever fazer, alguém, algo, para algum propósito).

(6g) Luiz Silva pergunta (dever fazer, Luiz Silva, QU, para formalizar o contrato de gaveta de Luiz Silva com a proprietária do imóvel).

(6h) 0 enunciador 1 afirma que o enunciador 2 pergunta algo (dever fazer, alguém, algo, para algum propósito). 
(6i) 0 jornalista afirma que Luiz Silva pergunta (dever fazer, Luiz Silva, QU, para formalizar o contrato de gaveta de Luiz Silva com a proprietária do imóvel).

Para o consulente, a resposta de sua dúvida é a dimensão relevante. Ele envia a carta, porque entram em jogo suposições sobre o funcionamento desse gênero no jornal. Se a necessidade de uma resposta é a dimensão relevante mais fundamental que catalisa o texto, a existência de práticas sociais de fornecimento de respostas nos jornais viabiliza a interação. 0 jornalista, baseado nas configurações do gênero, processa a mediação.

Veja-se a resposta do enunciador 3 .

(9) É de praxe que ao se formalizar um contrato de gaveta, o vendedor do imóvel outorgue no mesmo ato uma procuração com poderes necessários para o comprador representá-lo em todos os atos relativos à efetivação do negócio.

(10) Acreditamos que no caso do leitor essa procuração deva existir, o que resolveria o problema.

(11) Sem essa procuração o leitor não poderá sequer efetivar a venda através de escritura pública.

(12) Nesse caso, a única solução seria ajuizar uma ação de adjudicação compulsória, na qual o leitor usaria o documento que tem para obter a escritura definitiva.

(13) De posse, então, da sentença judicial que the outorga a escritura definitiva, o leitor deverá obter da CEF a quitação.

(14) Luiz Wanis, advogado.

A resposta gira em torno do constituinte lógico relevante do enunciado (6), que é preenchido de duas formas, pois há duas possibilidades de solução, conforme Luiz Silva tenha ou não 'uma procuração com poderes necessários para o comprador representá-lo em todos os atos relativos à efetivação do negócio'.

(15a) Luiz Silva deve fazer algo para formalizar o contrato de gaveta de Luiz Silva com a proprietária do imóvel.

(15b) Luiz Silva deve usar a procuração da proprietária do imóvel com poderes necessários para Luiz Silva representar a proprietária do imóvel em todos os atos relativos à efetivação do negócio para formalizar o contrato de gaveta de Luiz Silva com a proprietária do imóvel, caso tenha uma procuração da proprietária do imóvel com poderes necessários para Luiz Silva representar a proprietária do imóvel em todos os atos relativos à efetivação do negócio.

(15c) Luiz Silva deve ajuizar uma ação de adjudicação compulsória, na qual [na ação de adjudicação compulsória Luiz Silva usaria o documento que Luiz Silva tem para Luiz Silva 
obter a escritura definitiva do imóvel e, então, Luiz Silva deve obter da Caixa Econômica Federal a quitação do financiamento e, então, Luiz Silva deve registrar o imóvel [...], caso não tenha uma procuração [...].

Como se pode conferir, várias suposições são mobilizadas para alcançarem-se essas formulações (que os possíveis atos para formalização do contrato de gaveta incluem obter a escritura, quitar o financiamento e registrar o imóvel, por exemplo). Logo, textos são apenas peças de evidência ou pistas constitutivas do input do processo de compreensão, fornecendo parte dos dados de natureza lógico-conceitual para a fase inferencial da interpretação. A interpretação da carta não decorre exclusivamente dos elementos textuais, mas de todo um conjunto de conhecimentos enciclopédicos sobre o modo de funcionamento de registros e financiamentos de imóveis ${ }^{8}$.

\section{Respostas diretas e indiretas: Opção ou constrangimento?}

A noção de gênero, enquanto forma textual padronizada, típica e inteligível de atos de fala, está intimamente associada à noção de linguagem como ação social. Conforme Bazerman (2005), a produção, a circulação e o uso ordenado dos gêneros constituem parcialmente a atividade e a organização dos grupos sociais. Quando bem sucedidos, textos criam fatos sociais, isto é, são ações sociais significativas mediadas pela linguagem. Posto isso, retomo as respostas das cartas-consulta de Simoni (2004) para demonstrar como constrições de relevância interagem com constrições sociais, permitindo um fulcro por onde essas perspectivas de análise podem ser mutuamente beneficiadas.

0 jornalista transcreveu a resposta e 'forneceu as credenciais do especialista' no enunciado (14): “Luiz Wanis, advogado". Para a autora, isso caracteriza as cartas-consulta diretas. Perceba-se, entretanto, que uma resposta indireta seria possível pela explicitação do ato ilocucional implícito na forma lógica do enunciado da resposta em (15a-c), tal como em (15d).

(15d) O advogado Luiz Wanis afirma que Luiz Silva deve [...].

Na descrição (15d), que caracteriza as cartas-consulta indiretas, a resposta deixa de ser citada para ser relatada. Além disso, há duas consequências: textualmente, omitem-se as 'credenciais do respondente', que passam a compor o relato; inferencialmente, a interpretação da resposta é a interpretação de um relato: algo como em (15e).

(15e) $[\varnothing=$ A redação do Jornal $O$ Globo afirma que] o advogado Luiz Wanis afirma que Luiz Silva deve [...]. 
Essa opção seguramente está ao alcance das habilidades do jornalista, mas ele estaria livre para fazê-la conforme suas preferências? Argumento que não, pois a estrutura genérica é também um subproduto explícito de constrições sociais.

\subsection{Respostas indiretas}

Simoni (2004) coletou 68 exemplares de carta-consulta, publicadas entre os dias 2 e 14 de janeiro de 2000: 29 do Jornal Folha de S. Paulo e 39 exemplares do Jornal 0 Globo. Desse total, há 21 cartas-consulta indiretas: Nove cartas do caderno 'Sua Vez/Cartas' da Folha, de 2 de janeiro; e 12 cartas do caderno de Economia, subseção de Mala direta da seção 'Defesa do Consumidor' de 0 Globo, seis de 5 de janeiro e seis de 12 de janeiro.

Vejam-se as respostas coletadas na Folha de São Paulo?:

48 - A Volkswagen disse que contatou a concessionária Liberato e a instruiu sobre como proceder. A montadora solicita que o cliente procure o gerente de serviços, Nabar, que já está ciente do assunto.

49 - A General Motors disse que a peça a que o cliente se refere é importada e está sujeita a tributos, o que encarece seu preço.

50 - A Volkswagen disse que seus veículos de passeio têm garantia de 12 meses, sem limite de quilometragem, condicionada à execução das inspeções previstas. Segundo a montadora, a garantia do veículo do cliente expirou em janeiro, que não cumpriu o plano de manutenção, ou seja, deixou de executar a inspeção dos 12 meses. [ $\varnothing$ ] Por isso, não houve possibilidade de concessão do atendimento na forma pleiteada.

51 - Segundo a Fiat, a informação disposta no manual de uso e manutenção está correta, mas foi desenvolvido um novo óleo para motores, batizado de 15W40, que conservaria 0 produto ainda melhor do que o recomendado ali.

52 - A Volkswagem disse que contatou o cliente e lhe prestou esclarecimentos sobre o caso. Também afirmou que acertou um horário para tratar o assunto, ainda na segunda quinzena deste mês.

53 - A Ford confirma a taxa para fornecimento de novo código.

54 - A General Motors disse que o cliente foi devidamente ressarcido, nos moldes normais do seguro contratado. $[\varnothing]$ O cliente recebeu um bem similar -uma Corsa Wagon $1999 / 2000$.

55 - A Ford ressaltou a importância de o cliente estar atento ao plano de manutenção do veículo. Segundo a montadora, o cliente não possui as revisões necessárias, e por esse motivo, não há como garantir que a manutenção tenha sido efetuada corretamente.

56 - A Volkswagem disse que, após uma série de negociações sem sucesso com o cliente 
para liquidar a dívida, foi movida uma ação de busca e apreensão do veículo. Julgada procedente, ela determina que a posse do bem apreendido seja do banco Volkswagem. $\S$ Segundo a montadora, posteriormente, o cliente moveu uma ação cível na Vara Especializada do Consumidor de Ithéus (BA). $[\varnothing] \mathrm{O}$ banco Volkswagem aguarda uma decisão judicial para, assim, tomar as providências que forem determinadas pela Justiça.

Os textos tendem a explicitar os verbos que indicam o ato ilocucional das empresas responsáveis pela resposta, nos moldes de 'A empresa disse (solicita, afirma, confirma, ressalta) que', salvo a carta 51, que apresenta a construção 'Segundo [a empresa]' e mantém implícito o ato de fala em jogo. Isso também ocorre nas sequências das respostas das cartas 50, 55 e 56, quando a autoria do relato já havia sido explicitada.

51 - Segundo [aquilo que] a [montadora] Fiat [disse], [...].

50 - A Volkswagen disse que [...]. Segundo [aquilo que] a montadora [Volkswagen] [disse], $[\ldots]$.

55 - A Ford ressaltou [...]. Segundo [aquilo que] a montadora [Ford][disse], [...].

56 - A Volkswagem disse que, [...]. § Segundo [aquilo que] a montadora [Volkswagen] [disse], [...].

Como prevê o 'princípio de relevância', o ato ilocucional pode ser alçado à explicatura, quando já houver sido apresentado à esquerda e for de fácil recuperação. Os casos marcados com '[Ø]' demonstram essa estratégia e são reapresentados a seguir.

50 - A Volkswagen disse que [...]. Segundo a montadora, [...]. [ $\varnothing=A$ Volkswagen disse que $]$ Por isso, não houve possibilidade de concessão do atendimento na forma pleiteada.

54 - A General Motors disse que [...]. [ $\varnothing=$ A General Motors disse que] 0 cliente recebeu um bem similar - uma Corsa Wagon 1999/2000.

56 - $A$ Volkswagem disse que, [...]. § Segundo a montadora, [...]. $[\varnothing=A$ Volkswagem disse que] 0 banco Volkswagem aguarda uma decisão judicial para, assim, tomar as providências que forem determinadas pela Justiça.

Observem-se as respostas coletadas em 0 Globo.

Dia 5 de janeiro:

57 - A ATL afirma que entrou em contato com o cliente para que ele vá até uma loja da empresa para fazer a troca da bateria.

58 - A Brastemp esclarece que a questão está em processo de solução com a substituição do produto, conforme combinado com a consumidora. 
59 - A Bozano/Simonsen informa que depois de sanado o equívoco no pagamento do prêmio, houve um acordo com a cliente.

60 - O Banco do Brasil informa que a administração da agência Ramos já regularizou a conta do cliente, que ficou satisfeito com o atendimento.

61 - O Carrefour esclarece que o Código de Defesa do Consumidor não define a forma de afixação dos produtos, porém estabelece que a oferta e a apresentação dos mesmos devem assegurar informações claras e precisas, da mesma maneira que o Carrefour procede. $[\varnothing=0$ Carrefour esclarece que] 0 código de barras é um sistema mais seguro do que a etiquetagem individualizada dos produtos, considerando que o hipermercado comercializa em média 35 mil itens.

62 - A CERJ informa que já solucionou a questão.

Dia 12 de janeiro

63 - A Carvalho Hosken informa que recebeu uma correspondência do reclamante em 17 de dezembro de 99. A construtora afirma que todos os clientes do empreendimento Rio 2 merecem respeito, sejam eles de origem Encol ou não. [ $\varnothing=A$ Carvalho Hosken informa que] Tanto assim que a Carvalho Hosken mantém um departamento comercial com dois pontos de atendimento, um no próprio empreendimento (Stand Principal - tel. 421-2424) e outro no Centro da Cidade (Av. Rio Branco 37, $12^{\circ}$ andar, tel: 518-6043). A empresa solicita que o leitor agende um horário que lhe seja conveniente - mesmo aos sábados, domingos ou feriados - com um de seus atendentes. "Temos a convicção de que acharemos a melhor solução para ambas as partes”, afirma a empresa.

64 - A Cônsul afirma que adotou todas as providências necessárias e garante que a questão apresentada já foi devidamente solucionada, de acordo com o desejo do leitor.

65 - A Bradesco Seguros informa que a proposta do segurado em questão foi entregue à seguradora em 18 de novembro de 99 e implantada em 2 de dezembro de 99 . [ $\varnothing=$ A Bradesco Seguros informa que] Nessa data, foram emitidos e enviados a apólice e o respectivo cartão para utilização do seguro.

66 - O Bradesco Visa informa que entrou em contato com a cliente e que o assunto já foi resolvido.

67 - O Banco do Brasil informa que a inscrição do CPF do Sr. Carlos Alberto Pires de Castro no Serasa foi resolvida em 18 de outubro de 98. A instituição garante ainda que o CPF em questão não está inscrito em nenhum órgão de proteção ao crédito.

68 - A Lojas Americanas informa que na aceitação do cheque da leitora foram consultados os gerentes da referida loja e não foi identificada nenhuma ocorrência neste sentido. [ $\varnothing=A$ Lojas Americanas informa que] Todo o negócio Lojas Americanas é focado em vendas, alega a empresa, que, por isso, estranha a descrição da cliente. $[\varnothing=A$ Lojas Americanas informa que] 0 que pode ter ocorrido é um erro de comunicação entre 0 caixa e a gerência. 
Verbos 'dicendi' são encontrados em todas as respostas, sobressaindo-se os verbos: afirmar, esclarecer e informar, além de garantir e solicitar. As respostas de 0 Globo tendem a ser mais curtas. Somente as respostas $61,63,67$ e 68 possuem mais de uma sentença. Nelas, apenas a estratégia de omissão do ato de fala pode ser observada.

Na resposta 63, a mais longa, há o único caso de citação direta, que é seguida da explicitação do respectivo ato de fala.

63 - [...] "Temos a convicção de que acharemos a melhor solução para ambas as partes", afirma a empresa [Carvalho Hosken].

Em todas as 21 respostas, o respondente E3 é pessoa jurídica e não se explicitam as credenciais do responsável pela informação dentro da organização. Isso sugere que, se a resposta provém de uma entidade jurídica: o movimento retórico de 'fornecer a resposta' é formatado como discurso relatado, o enunciador jurídico é alçado ao elemento mais à esquerda (a primeira informação do relato), e as credenciais da fonte são omitidas ${ }^{10}$. Algo como em (16a-b):

(16a) $O$ enunciador jurídico afirma que $P$.

(16b) $[\varnothing=$ A Redação afirma que $]$ o enunciador jurídico afirma que $P$.

Além disso, 19 cartas são exposições públicas de um litígio, sem formulação de pergunta direta ou indireta. Veja-se a carta-consulta 62:

62 - Após ter me dado o prazo de oito dias, a CERJ até agora não ligou a luz de minha nova casa (poste próprio), sendo que o pedido foi feito no dia 23 de novembro. Estamos no escuro! Márcia Jorio Villares da Costa, Rio (O Globo, Economia/Defesa do Consumidor (Mala Direta), 5 jan. 2000, p. 26)

Em (62), o que se tem é uma queixa. Algo como:

$\mathrm{S}_{1}$ - A CERJ deu prazo de oito dias para ligar a luz da casa de Márcia Jorio Villares da Costa, Rio de Janeiro, em 23 de novembro de 1999;

$\mathrm{S}_{2}$ - A CERJ não ligou a luz da casa de Márcia Jorio Villares da Costa, Rio de Janeiro, em 5 de janeiro de 2000;

$\mathrm{S}_{3}$ - Se $\mathrm{S}_{1}$ e $\mathrm{S}_{2}$, então $\mathrm{S}_{5}$ (por modus ponens conjuntivo);

$\mathrm{S}_{4}-\mathrm{Se} \mathrm{S}_{2}$, então $\mathrm{S}_{5}$ (por eliminação-e);

$\mathrm{S}_{5}$ - A CERJ não cumpriu o prazo de oito dias (por afirmação do antecedente). 
Aqui, o protesto sobrepõe-se à consulta, ambos admitidos somente por inferência:

$\mathrm{S}_{1}$ - A CERJ não ligou a luz da casa de Márcia Jorio Villares da Costa, Rio de Janeiro, em 5 de janeiro de 2000;

$\mathrm{S}_{2}$ - 0 jornal $O$ Globo publicou a queixa de Márcia Jorio Villares da Costa, Rio de Janeiro, em 5 de janeiro de 2000;

$\mathrm{S}_{3}$ - Se $\mathrm{S}_{1}$ e $\mathrm{S}_{2}$, então $\mathrm{S}_{5}$ (por modus ponens conjuntivo);

$\mathrm{S}_{4}-\mathrm{Se}_{2}$, então $\mathrm{S}_{5}$ (por eliminação-e);

$\mathrm{S}_{5}$ [+ forte] - Márcia Jorio Villares da Costa, Rio de Janeiro protesta que a CERJ ligue a luz da casa de Márcia Jorio Villares da Costa, Rio de Janeiro, em 5 de janeiro de 2000 (por afirmação do antecedente).

$\mathrm{S}_{5}$ [- forte] - Márcia Jorio Villares da Costa, Rio de Janeiro consulta [...] (por afirmação do antecedente).

A publicação da carta traz para o foro público antes a situação de uma reclamante que demanda uma solução de um conflito do que a de uma consulente que demanda uma explicação. $\mathrm{Na}$ carta, há uma relação descritiva entre a posição do reclamante e um estado desejável de coisas do mundo, o que lhe confere caráter de solicitação e não de consulta. Mais ainda, trata-se de um protesto, porque tornar pública essa situação é mais do que pedir uma solução, é exigi-la. A CERJ não ficou insensível ao ultimato e solucionou a questão, minimizando o desgaste público da contenda. O Globo publica: 'A CERJ informa que já solucionou a questão'.

Todavia, nos dois exemplos abaixo, ambos da Folha de S. Paulo, a dúvida é explícita e a queixa implícita.

51 - "Meu irmão tem um Palio 1.6 16V, ano 97, assim como o leitor da Folha Arquimedes Oliveira, que teve sua carta publicada na edição de 21 de novembro. Nela a Fiat recomenda o uso de óleo Selenia 15W40. Acontece que o seu manual (págs. F-23 e F-25) recomenda o uso do óleo 20W50. Quero saber se a Fiat está publicando informações errôneas em seus manuais ou se publicou no jornal recomendações erradas".

Pedro Chirae (Pacaembu, SP).

Resposta

Segundo a Fiat, a informação disposta no manual de uso e manutenção está correta, mas foi desenvolvido um novo óleo para motores, batizado de $15 \mathrm{~W} 40$, que conservaria o produto ainda melhor do que o recomendado ali.

53 - "Comprei um Escort 97, com motor Zetec. Na semana passada, fiz um reparo no sistema elétrico em um mecânico particular. 0 serviço foi realizado com sucesso, mas o rádio não funcionou mais. 
Recorri à autorizada Souza Ramos e fui informado de que seria necessário o código para acessar o equipamento. Para obter a numeração, é cobrada uma taxa de R\$ 30 . Isso não deveria ser um serviço gratuito da Ford?"

Paulo Henrique Soares (Campinas, SP)

Resposta

A Ford confirma a taxa para fornecimento de novo código.

Veja-se que Paulo Soares não apenas questiona se a cobrança da taxa está correta, ele protesta implicitamente que não está; Pedro Chirae não apenas consulta qual o óleo mais adequado, mas protesta que há duas informações diferentes. Esse matiz de conflito (queixa, reclamação, protesto, litígio) não se encontra nas cartas-consulta diretas de Simoni (2004).

Em suma, em nenhum das cartas indiretas, a resposta foi dada por especialistas, mas por pessoas jurídicas envolvidas numa contenda. Em geral, o jornalista funciona como moderador de um conflito. 0 reclamante/consulente apresenta uma demanda pública de algo de que discorda. A resposta, mais do que informação ou resolução de dúvida é uma declaração pública da posição da organização, onde há uma relação descritiva entre a posição dessa organização e um estado de coisas do mundo que minimiza ou resolve o conflito.

\subsection{Respostas diretas}

Simoni (2004) coletou 47 exemplares de cartas-consulta diretas. Desses, apenas sete não são assinados: quatro compõem o caderno 'Boa Viagem' de 0 Globo, sobre dicas de viagem; um, sobre luz estroboscópica em vidros traseiros de automóveis, compõe o caderno 'Carroetc', de O Globo; e dois compõem o caderno 'Canal Aberto’ da Folha, publicada em 12 de janeiro. Vejase, por exemplo, a carta-consulta 9:

Curitiba

Gostaria de indicações de pousadas ou hotéis do tipo duas estrelas, com preços bem em conta, em Curitiba.

Patrícia

Via Internet

Curitiba reúne 81 hotéis classificados com estabelecimentos que vão do alto luxo ao albergue. Informações turísticas e indicações de hospedagem podem ser obtidas, por telefone, na Central do Disque Turismo (OXX41) 200-1511. Na internet: www.viaje.curitiba.pr.gov.br 
As demais 40 cartas são assinadas por especialistas (médicos, psicólogos ou advogados) a exemplo do caso da consulta sobre o 'contrato de gaveta' de Luiz Silva, respondida e assinada pelo advogado Luiz Wanis. 0 Caderno 'Folhateen/Saúde', da Folha, vale-se de Jairo Bouer, médico, e de Rosely Sayão, psicóloga. Bouer é tratado pelo jornalista E1 como colunista em um dos títulos: 'Colunista propõe um 2000 sem pisada de bola. Saiba como'. Em O Globo, Júlio Botelho e B. Piropo assinam uma carta cada no caderno 'Informática ETC'. 0 caderno 'Morar Bem' apresenta dois advogados: Luiz Wanis com nove cartas, em 2 de janeiro, e Pedro Cantisano com sete cartas, em 9 de janeiro. 0 caderno ‘Jornal da Família/Qual é o seu problema?’ apresenta no dia 2 de janeiro os doutores: Marco Antônio Fortes, duas respostas sobre urologia, Mário Ghelman, uma resposta sobre odontologia, Sérgio Rosenfeld e Eduardo Sadigurschi, uma resposta cada sobre reumatologia, Roberto German, uma resposta sobre clínica geral, e Clovis Munhoz, uma carta sobre ortopedia. Em 9 de janeiro, Aday Coutinho responde três consultas sobre urologia; Leonardo Tostes, duas cartas sobre endocrinologia e José Figueiredo Penteado, duas cartas sobre gastroenterologia.

Como não houve omissão de credenciais nos 40 casos cujas respostas advêm de especialidades para as quais os jornalistas não possuem formação, os dados sugerem que o jornalista fornece as credenciais toda vez em que a autoria da resposta é externa à redação e/ou fornecida por colunistas, consultores ou colaboradores ${ }^{11}$. Nesse caso, a estratégia de E1 (o jornalista) é alçar E3 (o especialista) à explicatura e fornecer suas credenciais (assinatura) no final do texto. Algo como (17a-c), a seguir:

(17a) P. Credenciais do especialista.

(17b) $[\varnothing=0$ especialista afirma que] P. Credenciais do especialista.

(17c) $[\varnothing=A$ Redação afirma que $][\varnothing=0$ especialista afirma que $]$ P. Credenciais do especialista.

Desse modo, as respostas são declarações onde há uma relação descritiva entre a posição do especialista e um estado de coisas do mundo a partir do ponto de vista de sua especialidade, cujo objetivo é a solução da dúvida do consulente.

Por sua vez, embora o estudo de Simoni (2004) não seja suficientemente longitudinal, a autoria pôde ser omitida em áreas como turismo, informática ou mecânica. Ausentes as credenciais, pode-se inferir que a resposta não é externa à redação ou não foi assumida como tal. Algo como (18a-b), a seguir:

(18a) $P$.

(18b) $[\varnothing$ = A Redação afirma que $P$. 
Vale questionar aqui se a responsabilidade jurídica da declaração é do jornal nesses casos, por que não optar pela formulação indireta? Aqui, a constrição é de ordem cognitiva. Omitindo-se a fonte da declaração, o primeiro candidato à autoria é a própria redação. Isso não é desejável nas cartas-consulta indiretas, porque a responsabilidade legal pela resposta é de organizações externas. Além disso, (18c) sugere (18d):

(18c) A Redação afirma que P.

(18d) $[\varnothing=$ A Redação afirma que] A Redação afirma que P.

Assim, explicitar a autoria da redação é uma redundância, um aumento injustificado de esforço de processamento sem ganho adicional de efeitos cognitivos ${ }^{12}$.

\section{CONCLUSÕES}

Para Bonini (2007), gêneros não são somente formas de transmissão de mensagens, mas princípios aglutinadores de um conjunto de ações e práticas sociais onde modos de edição e de leitura sobrepõem-se a relações mais fundadoras como as de pergunta/resposta. Apesar disso, não se pode esquecer que essas correlações decorrem da ação pragmático-cognitiva de escritores/leitores. Neste estudo, argumento que relações de relevância subjazem a elaboração do gênero carta-consulta.

No que se refere às respostas, analisei as diferenças entre respostas diretas e indiretas que, segundo Simoni (2004), caracterizam dois subtipos de cartas-consulta nos jornais 0 Globo e Folha de S. Paulo. Os achados sugerem que as diferenças apontadas decorrem do tratamento dado às fontes das respostas, de tal modo que: a) se a fonte for pessoa jurídica, ela é explicitada linguisticamente no início da resposta, a resposta é relatada, e as credenciais não são apresentadas no final da resposta; b) se a fonte for pessoa física, especialista em determinada área e, possivelmente, colaborador contumaz ou colunista assumido, a resposta é citada, e as credenciais são apresentadas no final da resposta; e, c) se a fonte for a própria redação do jornal, a resposta é citada e as credenciais são omitidas.

Como a análise retórica de Simoni (2004) baseia-se apenas na estrutura linguística da forma lógica dos enunciados das cartas (as sentenças), ela vê razões suficientes para descrever dois subtipos de carta com passos retóricos diversos no movimento retórico de fornecer a resposta, sem explicar razões para essas configurações. Todavia, ao se considerar o nível da explicatura ou da implicatura (no caso das respostas atribuídas à redação), é possível descrever e explicar estratégias diferentes de guiar a relevância, conforme as constrições do fazer jornalístico sobre a estrutura textual. 
Simoni (2004) atribui três papeis aos enunciadores: o jornalista (E1) conecta a consulta do leitor (E2) com a resposta de um especialista (E3). Isso parece valer para todas as cartas-consulta diretas, ainda que seja discutível a especialização dos jornalistas em respostas atribuídas à redação. Na quase totalidade das cartas-consulta indiretas: o leitor (E2) se queixa ou protesta (trata-se de uma demanda implícita, antes que uma consulta), o jornalista (E1) medeia um conflito e a empresa (E3) elabora uma réplica. As duas exceções encontradas aproximam-se do modelo consulta/resposta, mas tanto a consulta ocorre em meio a uma demanda, quanto a resposta equivale a uma satisfação da empresa envolvida nessa demanda.

Diante desse cenário, a definição mesma de carta-consulta poderia ser repensada como 'uma carta do leitor, publicada em seções específicas de um jornal, contendo consultas ou demandas, para as quais se transcrevem ou relatam respostas ou réplicas da redação desse jornal, de colaboradores especialistas ou de entidades envolvidas na demanda'.

Essa definição permitiria agrupar consultas com demandas implícitas e demandas com consultas implícitas, sendo reconhecidos dois subtipos: cartas-consulta com respostas diretas e cartasconsulta com respostas indiretas. Esse refinamento não é trivial, pois é inadequado dizer que as cartas-consulta integralmente sejam diretas ou indiretas. A distinção se refere apenas ao terceiro movimento retórico da carta, o de 'fornecer a resposta', e não à carta toda. Ou seja, por carta-consulta indireta, teríamos de identificar pelo menos um exemplar com o esquema:

(20) $O$ consulente pergunta se $P$. $O$ respondente afirma que $Q$.

Esse tipo de formatação não ocorreu em Simoni (2004) supostamente por razões similares às que tornam explícitas as credenciais dos colaboradores do jornal nas respostas: todos os consulentes/demandantes são pessoas físicas identificadas.

Assim, 'cartas-consulta com respostas diretas' poderiam ser definidas como 'uma carta do leitor, publicada em seções específicas de um jornal, contendo consultas, para as quais se transcrevem respostas da redação desse jornal ou de colaboradores especialistas'. Nelas, a consulta é explícita e as credenciais são omitidas sempre que a resposta puder ser atribuída à redação. 'Cartas-consulta com respostas indiretas' poderiam ser definidas como 'uma carta do leitor, publicada em seções específicas de um jornal, contendo demandas ou consultas, para as quais se relatam réplicas ou respostas das entidades envolvidas nas demandas ou consultas'. $\mathrm{Na}$ maioria delas, a demanda é explícita e a consulta se obtém por inferência. 


\section{REFERÊNCIAS BIBLIOGRÁFICAS}

Bazerman, C. (2005). Atos de fala, gêneros textuais e sistemas de atividades: Como os textos organizam atividades e pessoas. Em A. Dionízio \& J. C. Hoffnagel (Eds.), Gêneros textuais, tipificação e interação (pp. 19-46). São Paulo: Cortez.

Bazerman, C., Bonini, A. \& Figueiredo, D. C. (2009). Genre in a changing world. Fort Collins: The WAC Clearinghouse; West Lafayette; Parlor Press.

Blass, R. (1990). Relevance relations in discourse: A study with special reference to Sissala. Cambridge: Cambridge University Press.

Bonini, A. (2007). A relação entre prática social e gênero textual: Questão de pesquisa e ensino. Veredas (UFJF), 11(2), 1-21.

Carston, R. (1988). Implicature, explicature, and truth-theoretic semantics. Em R. Kempson, (Ed.), Mental representations: The interface between language and reality (pp. 155181). Cambridge: Cambrige University Press.

Folha de S. Paulo. (1992). Novo manual da redação. São Paulo: Folha de S. Paulo.

O Globo \& Garcia, L. (2000). Manual de redação e estilo. São Paulo: Globo.

Rauen, F. (2009). Relevance and genre: Theoretical and conceptual interfaces. Em C. Bazerman, A. Bonini \& D. C. Figueiredo (Eds.), Genre in a changing world (pp. 57-77). Fort Collins: The WAC Clearinghouse; West Lafayette; Parlor Press.

Rauen, F. (2007). Teoria da relevância e gêneros textuais: interfaces possíveis. Trabalho apresentado no $4^{\circ}$ Simpósio Internacional de Estudos de Gêneros Textuais, Universidade do Sul de Santa Catarina, Tubarão, Brasil.

Simoni, R. (2004). Uma caracterização do gênero carta-consulta nos jornais O Globo e Folha de S. Paulo, 2004. Dissertação de Mestrado, Programa de Pós-Graduação em Ciências da Linguagem, Universidade do Sul de Santa Catarina, Tubarão, Brasil.

Sperber, D. \& Wilson, D. (1995). Relevance: Communication \& cognition. Oxford: Blackwell.

Swales, J. (1990). Genre analysis: English in academic and research settings. New York: Cambridge University.

Swales, J. (1992). Re-thinking genre: Another look at discourse community effects. Em J. Swales (Ed.), Re-thinking genre colloquium (pp. 197-220). Otawa: Carleton University.

Swales, J. (1998). Other floors, other voices: A textography of a small university building. Mahwah: Lawrence Earlbaum.

Wilson, D. (2004). Pragmatic Theory. London: UCL Linguistics Dept [em línea]. Disponível em: http://www.phon.ucl.ac.uk/home/nick/pragtheory/ 


\section{NOTAS}

1 'Contrato de gaveta' é um acordo entre quem está pagando um financiamento, o vendedor, e outra pessoa, o comprador, que assume o pagamento desse financiamento por meio de uma combinação verbal ou contrato particular. É um acordo de risco que depende da confiança entre as partes, pois o contrato pertence ao vendedor. 0 comprador arrisca-se quando o vendedor age de má fé, morre ou muda-se para local ignorado (como é o caso da consulta de Luiz Silva). 0 vendedor arrisca-se quando o comprador deixa de pagar as prestações ou taxas de condomínio. A jurisprudência brasileira considera que o comprador tem o direito de reclamar a posse do imóvel quando há um contrato ou compromisso de compra e venda mesmo não registrado. Contratos desse tipo devem ser guardados numa gaveta até serem quitados e formalizados oficialmente. Daí a expressão.

2 Sperber e Wilson (1995) defendem que somente regras dedutivas entram em cena nos processos inferenciais espontâneos, em especial a regra de eliminação-e $(\mathrm{P} \wedge \mathrm{Q} ; \mathrm{Q}$ ou $\mathrm{P} \wedge \mathrm{Q} ; \mathrm{P})$ e a regra de modus ponens $(\mathrm{P} \rightarrow \mathrm{Q} ; \mathrm{P} ; \mathrm{Q})$.

3 A cláusula (b) da presunção de relevância ótima gera ainda duas consequências: a) a de que a primeira interpretação satisfatória que o leitor obtém é a única interpretação satisfatória; e b) a de que o esforço adicional de processamento deve ser compensado por efeitos adicionais (ou diferentes) (Wilson, 2004). A primeira consequência prevê que se há uma interpretação relevante do modo esperado mais saliente ou imediatamente acessível, ela é a única interpretação razoável, bloqueando outras interpretações. A segunda consequência prediz que se há um esforço adicional, pode-se assumir que o escritor pretende um efeito adicional ou diferente impossível com uma formulação mais direta.

4 Uma explicatura é uma forma lógica proposicional ou semanticamente completa decorrente de várias operações pragmáticas: atribuição de referência, desambiguação, resolução de indeterminâncias, interpretação metafórica, enriquecimentos de elipses, incluindo-se descrições de nível mais alto representando $o$ ato de fala subjacente ao enunciado. Implicaturas são inferências que extrapolam o desenvolvimento da forma lógica. Nesses casos, a forma lógica proposicional compõe uma premissa implicada a partir da qual se gera dedutivamente uma conclusão implicada, possivelmente a interpretação última pretendida pelo escritor.

5 FGTS (Fundo de Garantia por Tempo de Serviço) é um fundo constituído pelos depósitos mensais de empregadores em contas da Caixa Econômica Federal (CEF, Caixa) em nome dos seus empregados. A conta do FGTS visa dar suporte financeiro aos trabalhadores em caso de demissão sem justa causa e pode ser usada para quitar financiamentos da Caixa para aquisição de moradia.

6 Enunciados podem ser: descrições de estados de coisas do mundo real ou ficcional ou descrições de estados de coisas desejáveis; ou podem ser interpretações de pensamentos ou enunciados atribuídos ou interpretações de pensamentos desejáveis.

7 Sperber e Wilson (1995) distinguem: perguntas sim-não (com uma forma lógica e uma forma proposicional total); e perguntas-Qu (com uma forma lógica, mas nenhuma forma proposicional total).

8 Blass (1990) propõe que a noção de textualidade fundamenta-se em relações de relevância entre texto e contexto. De um lado, o critério de consistência com o princípio de relevância seleciona e restringe o conjunto de suposições a serem utilizadas pelo leitor; de outro, o comportamento verbal do escritor é restringido pela expectativa de relevância do leitor.

9 Respostas indexadas conforme a ordem estabelecida em Simoni (2004). 
10 No tópico 'respeito às pessoas', o 'Manual de redação e estilo' de 0 Globo destaca que é preciso "distinguir uma instituição ou um grupo de pessoas que fazem parte dele". [...] "Pessoas falam por si mesmas, salvo quando dispõem de representação incontestável” (2000: 115).

110 'Novo manual da redação' da Folha de S. Paulo define colaborador como "pessoa que presta serviço a um meio de comunicação sem relação de emprego" (1992: 132). Não é preciso ser jornalista para essa caracterização. 0 jornal solicita textos a colaboradores, bem como pode publicar artigos enviados espontaneamente. Para o jornal, "o artigo de colaborador pode exigir pé biográfico", este definido como parte final de um texto onde "são fornecidas ao leitor informações sobre o autor ou articulista, quando este não pertence à equipe do jornal". Na Folha, "todo personagem de notícia deve ser identificado pela profissão, cargo, função ou condição" (1992: 80).

12 Exceto se o jornal fizesse parte do conflito e tivesse que se posicionar. Todavia, algo desse tipo supostamente não seria publicado como carta-consulta. 